\title{
FORMAÇÃO DE EDUCADORES PARA A EDUCAÇÃO PROFISSIONAL: A ARTICULAÇÃO ENSINO-PESQUISA-EXTENSÃO
}

\author{
Deloize Lorenzet*; Felipe Andreolla \\ *E-mail: delolorenzet@hotmail.com \\ Instituto Federal de Educação, Ciência e Tecnologia Sul-Rio-Grandense; Universidade Federal do Rio \\ Grande do Sul \\ DOI: $10.15628 /$ rbept.2020.6136
}

Artigo submetido em: 21/07/2017 e aceito em 27/03/2020

\section{RESUMO}

\begin{abstract}
Este artigo analisa alguns fatores necessários para a formação do educador que atua na educação profissional. O mesmo precisa estar instrumentalizado por conhecimentos das áreas técnicas, em formação específica, mas também, necessita conhecer sobre os saberes das áreas didáticas e pedagógicas numa atuação engajada politicamente. Neste processo, também enfocamos os pilares da educação profissional que precisa conhecer: trabalho e pesquisa como princípios educativos, ciência, cultura e tecnologia. Por fim, dialogamos acerca da articulação entre o ensino, a pesquisa e a extensão, na referida modalidade de ensino. Para realizar tais propósitos utilizamos a metodologia da análise bibliográfica e documental problematizando e refletindo de modo aberto, em diálogo entre algumas postulações teóricas e a prática. Como resultados pontuamos que o educador da educação profissional precisa de sólida formação inicial e de formação continuada a fim de estar permanentemente se qualificando em virtude das alterações contínuas da educação, da sociedade e do mundo do trabalho.
\end{abstract}

PALAVRAS-CHAVE: Formação de Educadores, Trabalho, Educação Profissional.

\section{TEACHER TRAINING FOR VOCATIONAL EDUCATION: THE ARTICULATION BETWEEN TEACHING, RESEARCH AND EXTENSION}

\begin{abstract}
This article analyzes some essential factors related to the formation of educators engaged in professional education. The challenge is getting by knowledge of the technical areas, in particular training, but you also need to know about the knowledge of methodology and pedagogical areas. This complexity we focus on the pillars of education: labor and research as educational principles, science, culture, and also technology. Finally, we dialogue about the link between teaching, research and extension, a special type of education. To accomplish these purposes we use the methodology with questioning literature and reflecting explanatory mode. As we pointed out that the results professional education teacher needs solid initial training and continuing education in order to be permanently qualifying because of continuous changes of education, society and the world of work
\end{abstract}

KEYWORDS: Teacher Training, Work, Professional Education. 


\title{
1. CONSIDERAÇÕES INTRODUTÓRIAS
}

\author{
"Para quién estáis trabajando? \\ You sustengo que el único objetivo de la ciência \\ Es aliviar las fatigas de la existência humana" \\ (Galileu Galilei, por Bertold Brecht).
}

Este artigo tem por objetivo refletir acerca da formação de educadores para a educação profissional. Este tema é pertinente e exige maior compreensão, em virtude da expansão projetada pelo Plano Nacional de Educação, para triplicar entre 2014-2024, o índice de matrículas na educação profissional (EP) e para garantir qualidade e excelência. Esta modalidade de ensino exige uma formação de educadores diferenciada, em razão de que esses profissionais necessitam construir conhecimentos técnicos e didático-pedagógicos. Tais aspectos não estão hierarquizados (um inferior, outro superior), mas são fatores complementares.

A inserção da educação profissional na sociedade brasileira precisa ser coerente com um projeto inclusivo e de democratização da ciência e da tecnologia, pois há confrontos, convergências e afastamentos que envolvem o mundo do trabalho, por vezes cingido pelo emprego, desemprego, subemprego. Esta sociedade está marcada por profundas desigualdades sociais, econômicas e culturais, como também, há uma constante ameaça acerca da manutenção dos direitos básicos para uma vida digna. Problemas como a miséria, a violência, a exploração também instauram um cenário perverso de medo a ser superado diariamente. Apesar disso, como enfatizou esta epígrafe, trabalhamos para amenizar as fadigas da existência humana. Neste contexto está inserida a educação profissional, como uma das ferramentas que propicia condições e potencializa a qualificação para o trabalho, na tentativa de capacitar para a vida produtiva e ampliar e melhorar a qualidade de vida.

O documento Diretrizes Curriculares Nacionais, publicado em 2013, torna-se significativo ao enfatizar que:

\footnotetext{
Atualmente, não se concebe uma educação profissional identificada como simples instrumento de política assistencialista ou linear ajustamento às demandas do mercado de trabalho, mas sim como importante estratégia para que os cidadãos tenham efetivo acesso às conquistas científicas e tecnológicas da sociedade. Impõe-se a superação do enfoque tradicional da formação profissional baseado apenas na preparação para execução de um determinado conjunto de tarefas a serem executadas. A educação profissional requer, além do domínio operacional de um determinado fazer, a compreensão global do processo produtivo, com a apreensão do saber tecnológico, a valorização da cultura do trabalho e a mobilização dos valores necessários à tomada de decisões no mundo do trabalho (BRASIL, 2013, p.209).
} 
Observamos a preocupação com uma educação emancipadora, porém, na prática, nem todos os educadores e nem todas as instituições possuem tal concepção. A própria citação resgata que atualmente, a educação profissional não é assistencialista, no entanto, sua origem histórica teve este objetivo e ainda há resquícios deste período em determinados espaços.

A educação profissional constitui-se como uma modalidade com grande relevância social e estratégica para a conquista científica e tecnológica. Em virtude disso, torna-se imprescindível dialogar acerca da formação dos seus educadores, para que eles conheçam que esta modalidade educativa tem muito a contribuir com a difusão dos conhecimentos científicos e tecnológicos e com as melhorias das condições de vida dos indivíduos.

Frente ao objetivo exposto no início, são formuladas algumas questões condutoras para a reflexão, análise e direção desse artigo, divididas em dois blocos:

a) Quais as especificidades da formação docente para a educação profissional? Quais as características elementares para estes educadores? Quais os pilares que sustentam a EP?

b) De que forma este educador pode planejar a articulação entre os processos de ensino, de pesquisa e de extensão? Como poderá organizar suas atribuições em torno destes três elementos de maneira a enriquecer a oferta curricular e tornando o processo de ensino-aprendizagem significativo?

Estruturalmente, para dar conta destas indagações, o respectivo artigo será dividido em duas partes: na primeira parte trataremos das especificidades da formação docente para a educação profissional e a formação continuada e alguns pilares que substantivamente apoiam esta modalidade de ensino. Na segunda parte deste artigo, trataremos da articulação entre o ensino, a pesquisa a extensão e da forma de utilizar este tripé para enriquecer a oferta curricular e impulsionar o processo de ensinoaprendizagem mais pertinente, contextualizado e significativo.

\section{AS ESPECIFICIDADES DA FORMAÇÃO DOCENTE PARA A EDUCAÇÃO PROFISSIONAL}

Iniciamos esta reflexão reportando-nos à Constituição Federal Brasileira de 1988, cujo artigo 205 explica que todas as formas de educação têm por princípio "o desenvolvimento pleno da pessoa, seu preparo para o exercício da cidadania e sua qualificação para o trabalho". Ou seja, todo processo de ensino visa desenvolver o ser humano integralmente, dar suporte para sua cidadania, e instrumentalizá-lo para o trabalho, não sendo esta uma especificidade restrita, exclusiva apenas à educação profissional. Entretanto, a qualificação para o trabalho deve ser ofertada com eficácia por esses profissionais.

As atribuições da educação são extremamente complexas e difíceis de serem desenvolvidas, pois envolvem uma atuação, um exercício que carece de engajamento 
político e competência técnica. Desta forma, utilizando termos freirianos, o educador não pode eximir-se de seu compromisso político da leitura do mundo para reduzir sua atuação com neutralidade científica, apenas para a leitura da palavra. Por vezes, percebemos que a formação deste professor é muito tecnicista, carente de concepções históricas, sociológicas, antropológicas, políticas e em estudos culturais, facilitando a subordinação ao sistema agindo num "piloto automático". Ser educador requer saberes pedagógicos e educacionais, conhecimentos científicos, indagação teórica, crítica e reflexiva. Tais saberes exigem dedicação, estudo e aprimoramento permanente. Deste modo, numa perspectiva de transformação social, é necessário que o docente da Educação Profissional seja "[...] um intelectual que domine seu campo científico específico, os saberes inerentes ao ato de ensinar e tenha o comprometimento éticopolítico com a classe trabalhadora, à qual ele pertence" (MOURA, 2014, p. 36).

Neste sentido, a formação de educadores possui um contexto temporal e espacial e ainda ocorre na interação entre os pares, como forma de desafio e superação constantes. Da mesma forma, a formação do educador é algo processual que não pode acontecer precipitadamente, mas deve ocorrer de modo inicial e continuado. Segundo Machado (2008, p. 70) "a referência mais forte que se tem é a de que a formação docente para a educação profissional deve-se dar em cursos especiais", ou seja, de modo fragmentado ${ }^{1}$. Frente a isso, ressaltamos a inexistência de políticas perenes e articuladas que tratem especificamente da formação dos docentes da educação profissional. Conforme destacam Damascena, Nascimento e Moura: "[...] engrossamos o coro dos que defendem a construção de ações e políticas perenes que visem contemplar as necessidades formativas tanto dos que já atuam na educação profissional quanto dos que podem vir a atuar" (DAMASCENA, NASCIMENTO E MOURA, 2017, p.3).

Ademais, o educador da educação profissional necessita de características como a sensibilidade, a ética, a integridade, criatividade e acompanhamento reflexivo com ressignificação de suas práticas pedagógicas e outras questões são plausíveis, como as relações sociais entre o mundo da educação e o mundo do trabalho. Para Araújo, esse profissional

[...] não pode moldar-se à feição de transmissor de conteúdos definidos por especialistas externos, mas compor-se por características em que seu papel de professor se combine com as posturas de: a) Intelectual; b) Problematizador; c) Mediador do processo ensino-aprendizagem; d) Promotor do exercício de liderança intelectual; e) Orientador sobre o compromisso social que a ideia de cidadania plena contém; f) Orientador sobre o comportamento técnico dentro de sua área de conhecimento. (ARAÚJJ, 2008, p. 59).

\footnotetext{
${ }^{1}$ A ideia de curso especial marcou a história da formação de professores para a Educação Profissional no Brasil, uma vez que neste campo admitem-se profissionais sem saberes da formação pedagógica, como também sem experiências da EP. Para aprofundamento na temática indicamos o artigo: MACHADO, L. R. S. Os desafios da formação dos professores para a EPT e o PROEJA. Disponível em: < http://www.scielo.br/pdf/es/v32n116/a05v32n116.pdf>. Acesso em 11 nov. 2019.
} 
Frente a isso, o trabalho deste profissional deve ser forjado num perfil que envolva múltiplas características e o comprometimento com a classe trabalhadora e a transformação social.

A educação profissional é uma modalidade de ensino amparada pela Lei de Diretrizes e Bases da Educação Nacional (Lei n. 9.394/1996). O artigo 39 da referida legislação explicita que a EP pode ser integrada às diferentes formas de educação, ou em diferentes níveis de ensino, dos mais elementares aos superiores. A ampliação do conceito de educação para além da escola, reconhecendo a dimensão formadora em outros espaços institucionais de convívio social, foi um princípio proposto e conquistado pelos movimentos populares. Além destas características, a educação profissional precisa estar integrada com os pilares do trabalho e da pesquisa como princípios educativos, da ciência, da cultura e da tecnologia. Como a EP possui estes vínculos, fundamentaremos etimologicamente e com outros referenciais tais conceitos basilares para o exercício da docência neste contexto.

Primeiramente, o trabalho e a pesquisa são referenciados como princípios educativos. O termo trabalho tem sua origem no vocábulo latino "tripaliu": denominação de um instrumento de tortura formado por três paus. Desse modo, originalmente, na Antiguidade, "trabalhar" significava ser torturado no tripaliu. Quem eram os torturados? Os escravos e os pobres que não podiam pagar os impostos. Assim, quem "trabalhava", naquele tempo, eram as pessoas destituídas de posses. A partir daí, essa ideia de trabalhar como ser torturado passou a dar entendimento não só ao fato de tortura em si, mas também, por extensão, às atividades físicas produtivas realizadas pelos trabalhadores em geral: camponeses, artesãos, agricultores, pedreiros etc. Atualmente ainda encontramos alguns traços de (pre)conceito em relação aos trabalhos braçais, considerados num senso comum de categoria inferior. Tal sentido foi de uso comum na Antiguidade e, com esse significado, atravessou quase toda a Idade Média. Só no século XIV começou a ter o sentido genérico que hoje lhe atribuímos, qual seja, o de "aplicação das forças e faculdades (talentos, habilidades, competências) humanas para alcançar um determinado fim".

Dando continuidade, a EP deve defender o pleno desenvolvimento cultural do trabalhador. O termo cultura etimologicamente remete a ação de cultivar, desenvolver plantas. Com o passar do tempo este termo latino recebeu a analogia de cultivar, cuidar da construção das capacidades educacionais e intelectuais. É a cultura, pois, produto do trabalho humano das interações históricas, e é o seu domínio, conhecimento de modo ativo que permite formar o dirigente omnilateralmente. Desta forma, é oportuno enfatizar que uma lógica interessante para a transformação social da classe trabalhadora é a que permite a integração entre as capacidades de pensar, pela cultura e as capacidades de produzir, por meio do trabalho. ${ }^{2}$

\footnotetext{
${ }^{2}$ Araujo e Rodrigues (2010) referenciam diversos autores que defendem esta maior integração entre o pensar e o fazer, tais como: Marx, Pistrak, Manacorda, Gramsci, Saviani. Para aprofundamento, sugerimos: ARAUJO, R. M. L.; RODRIGUES, D. S. Referências sobre Práticas Formativas em Educação Profissional: o velho travestido de novo frente
} 
Ao docente da educação profissional é essencial o aporte teórico oriundo da sociologia do trabalho. Ao fundamentarmos nossa concepção numa perspectiva crítica, com base em Marx, Thompson e Gramsci, podemos atribuir ao trabalho o processo de construção da existência humana em uma localização histórica e social, como concepções que buscam a integração, a unidade entre o pensar e o fazer, a escolarização e a profissionalização, a teoria e a prática.

\section{Para Ciavatta, a educação:}

[...] não pode ser reduzida às necessidades estritas do mercado de trabalho, ela não pode ser alheia às necessidades de sobrevivência e às exigências da produção econômica, como campo de onde os sujeitos sociais retiram os meios de vida. Em consequência, os dados locais, a identificação das oportunidades ocupacionais não é um dado desprezível, pelo contrário, é parte do processo educativo (CIAVATTA, 2004, p. 98).

Com isso, a educação profissional precisa estar preocupada com a produção econômica uma vez que os trabalhadores dependem deste setor para sobreviver. Entretanto não pode haver unilateralidade, precisa ponderar para que os aspectos econômicos não sejam avaliados em supremacia, em detrimento dos aspectos sociais, culturais, ambientais e humanos. É essencial que façamos uma análise: qual o sentido do trabalho? Há dignidade e relevância social no trabalho que realizamos? Entendemos o trabalho como criação? O que estamos produzindo? O trabalho colabora para dar sentido à vida?

O pesquisador Frigotto enfatiza que a educação precisa ser um instrumento de inclusão social, assim, necessitamos:

[...] reconhecer a diferença entre os sujeitos individuais e sociais não é o mesmo que legitimar a desigualdade. Pelo contrário, toma-se própria diferença, sobretudo, aquela que é fruto da desigualdade, como ponto de partida real para sua autossuperação naquilo que diz respeito ao sistema educativo. Sabemos que a desigualdade não é gerada na escola, mas na sociedade. A escola pode reforçá-la ou contribuir para sua superação (FRIGOTTO, 2005, p. 248).

Em razão desta argumentação, podemos indagar: a educação profissional que almejamos desenvolver serve como instrumento de transformação e superação social ou apenas pressupõe a manutenção das estruturas sociais?

Outra importante contribuição é desenvolvida por Kuenzer (1988, p.126), quando confirma que "a finalidade da escola que unifica cultura e trabalho é a formação de homens desenvolvidos multilateralmente, que articulem à sua capacidade produtiva as capacidades de pensar, de estudar, de dirigir ou de controlar quem dirige".

De acordo com as Diretrizes Curriculares Nacionais:

O trabalho é conceituado, na sua perspectiva ontológica de transformação da natureza, como realização inerente ao ser humano e como mediação no processo de produção da sua existência. Essa dimensão do trabalho é, assim, o

ao efetivamente novo. Disponível em: <http://www.bts.senac.br/index.php/bts/article/view/218/201>. Acesso em: 12 nov. 2019. 
ponto de partida para a produção de conhecimentos e de cultura pelos grupos sociais (BRASIL, 2013, p. 161).

Nessa perspectiva, cabe lembrar que o trabalho como fator de transformação da natureza, também precisa preocupar-se com questões de preservação biológica e sustentabilidade. É válido refletir: para que estamos formando? Para que estamos educando? Quais os princípios que sustentam nosso modo de agir na educação profissional?

Outro pilar aliado ao trabalho é o da pesquisa como princípio educativo, assim, neste enfoque, tendo a pesquisa como princípio educativo oportuniza-se elaboração de perguntas, a problematização, o desenvolvimento de projetos, práticas cooperativas e coletivas que deem respostas solidariamente à situações reais. Deste modo, a pesquisa como princípio educativo fortalece a construção da cultura argumentativa e a autonomia, tornando-se um diferencial na formação dos educandos. Na segunda parte deste texto nos dedicaremos mais detalhadamente a esta temática da pesquisa.

Dando sequência, o termo ciência deriva do termo latino "scientia"; cujo significado é conhecimento ou saber. Atualmente se designa por ciência todo o conhecimento adquirido por meio do estudo ou da prática, baseado em princípios científicos; também é atribuído o significado de ciência como origem da faculdade mental do conhecimento.

\section{Conforme as Diretrizes Curriculares Nacionais:}

A ciência, portanto, que pode ser conceituada como conjunto de conhecimentos sistematizados, produzidos socialmente ao longo da história, na busca da compreensão e transformação da natureza e da sociedade, se expressa na forma de conceitos representativos das relações de forças determinadas e apreendidas da realidade. O conhecimento de uma seção da realidade concreta ou a realidade concreta tematizada constitui os campos da ciência, que são as disciplinas científicas. Conhecimentos assim produzidos e legitimados socialmente ao longo da história são resultados de um processo empreendido pela humanidade na busca da compreensão e transformação dos fenômenos naturais e sociais. Nesse sentido, a ciência conforma conceitos e métodos cuja objetividade permite a transmissão para diferentes gerações, ao mesmo tempo em que podem ser questionados e superados historicamente, no movimento permanente de construção de novos conhecimentos (BRASIL, 2013, p. 162).

Por meio desta análise, amplia-se o conceito de ciência, como conhecimento que compreende os processos de transformação dos fenômenos naturais e sociais, já consolidados historicamente e no sentido da dinamicidade de construir novos saberes. Cabe neste momento, repensar: quais os usos da ciência na educação profissional? 0 que impulsiona a produção do conhecimento? Há um embasamento ético no aprimoramento e pesquisas científicas?

Do mesmo modo é pertinente refletir acerca do termo tecnologia. Esse tem sua origem do vocábulo grego "tekne"; que quer dizer técnica, arte, ofício, como um aproveitamento prático, um conjunto de saberes que permitem fabricar objetos e modificar o meio ambiente, com o objetivo de satisfazer as necessidades humanas. Convém destacar que, muitas pessoas utilizam este conceito limitadamente, apenas 
como sinônimo de tecnologias da informação, que são aquelas que permitem o tratamento e a difusão de informação por meios artificiais e que incluem tudo o que esteja relacionado com os computadores. É possível indagar: As tecnologias são produzidas para toda a população? São pensadas, projetadas para aprimorar o conforto e a qualidade de vida ou por outros interesses?

Nesse contexto, o educador da educação profissional, como qualquer outro educador, deverá associar conhecimentos teóricos e práticos, conforme postula o artigo 61 da LDB, mediante formação continuada em serviço, aproveitando suas experiências anteriores, no campo das instituições de ensino ou outras atividades. É essencial ressaltar que a identidade deste profissional vai se constituindo ao longo do contato com os educandos em sua prática. A reflexão sobre esta prática é uma ferramenta elementar na construção da trajetória formativa. Segundo Araujo (2008, p.61): "É necessário fortalecer os espaços de troca de experiências entre os profissionais desta modalidade de ensino, de modo a socializarem experiências cognitivas, metodológicas e afetivas".

Nessa perspectiva, este profissional deve estar instrumentalizado com o domínio dos conhecimentos técnicos, sobre sua área específica de atuação, mas também deve capacitar-se no sentido de compreender sobre planejamento, metodologias, procedimentos didáticos, currículo, formas de aprender, de ensinar e de avaliar, precisa engajar-se na construção do Projeto Político-Pedagógico da instituição, no Plano de Desenvolvimento Institucional, no Plano de Ação, na escolha e elaboração dos Projetos de Curso, nos Planos de Curso, entre outras atividades que muitas vezes são analisadas como burocráticas, mas que são fundamentais e dão um direcionamento para a instituição. Considera-se, ainda, determinante que o educador exponha sua opinião de forma democrática sobre as temáticas que possui maior interesse de aprimoramento, para que na formação continuada em seu espaço institucional, sejam contempladas suas necessidades.

Quanto maior for seu leque de metodologias, de concepções sobre o processo de aprendizagem, o conhecimento de tendências pedagógicas, maior será a diversidade de opções para realizar a escolha da forma mais adequada para desenvolver seus conteúdos. Sempre considerando o perfil dos educandos na escolha da metodologia mais ajustada e filosoficamente amparando-se em perspectivas da formação do trabalhador, enquanto sujeito ativo, ao invés da "fabricação" e do "adestramento" de um trabalhador passivo. É importante também conhecer a legislação que orienta esta modalidade de ensino, sua história, as configurações do arranjo produtivo local e regional, as modificações no cenário produtivo e tecnológico e do mundo do trabalho. Como também, entender as tendências, conquistas e desafios que influenciam significativamente o contexto social, econômico, cultural e científico. Frente a tantas faces que permeiam o cenário educacional salientamos que a formação complementar acontecerá continuamente, pois a educação como o modo de produção não é uma ciência estagnada, mas está em contínua formulação.

Nesse sentido, também torna-se essencial que o educador tenha clareza dos objetivos, do comprometimento político, do vínculo social, pois a neutralidade é conivente com a conservação das estruturas vigentes, direcionando a prática com as 
seguintes indagações: qual a concepção de ser humano desejo formar? Esta concepção está de acordo com a instituição que atuo? Para que serve a formação do educando? Para que tipos de experiências estou contribuindo em sua qualificação? A educação que defendo é a que prepara para a autonomia, o trabalho em equipe (cooperativo), a reflexão, o entendimento e a transformação da sociedade em dimensões de justiça social ou preparo meu educando para a submissão, o trabalho competitivo, o "acionamento do piloto automático" e a conservação das situações opressoras, com a ampliação das desigualdades sociais? Frente a isso, educar não pode ser uma ação simples, reducionista, impregnada pela lógica do aligeiramento, da rapidez, entretanto, é uma ação complexa, com inúmeras variáveis precisando da constante autoavaliação e discernimento acerca dos procedimentos didáticos.

Para Arruda (2012), a opção da educação omnilateral é um pré-requisito para a democratização da educação, como bem público e direito social:

\begin{abstract}
O desafio de desenvolver um processo educativo orientado para a democracia. Não a democracia liberal, de qualquer tipo que seja, mas a democracia em que todos e cada cidadão participem efetivamente como sujeitos - individuais e coletivo - da construção do universo, da sociedade e de si próprios enquanto pessoas, comunidade, povo e humanidade. Isto só poderá se realizar se todos participarem de uma educação omnilateral, que forneça e edifique uma visão global e universal associada à competência específica, que desenvolva na prática e na teoria a capacidade de escolher e decidir, que articule criativamente a igualdade de direitos com a diversidade de talentos e capacidades; uma educação em que todos disponham de todas as possibilidades da atividade cultural e do trabalho científico, capacitando-se, como sugere Gramsci, para ser 'governantes', quer dizer, para a tomada e a implementação das decisões, para a administração da produção e a construção da vida (ARRUDA, 2012, p. 100).
\end{abstract}

Conforme expresso, a educação profissional deve ofertar oportunidades de atividades culturais e do trabalho científico associado a saberes específicos, considerando o sujeito cidadão, produtor e construtor de sua vida. Sua formação será mais relevante e enriquecida na medida em que construir uma visão global e universal de mundo, onde consiga formular seus posicionamentos, desenvolver sua opinião e argumentos, numa capacidade crítica de escolhas e decisões.

Atualmente tornam-se extremamente preocupantes as características que estão sendo vinculadas à formação, muitas delas impregnadas pela lógica mercadológica, voltadas para a competitividade, flexibilidade, produtividade e eficiência, priorizando a produção em detrimento do sujeito. Castro, assim, denuncia:

\begin{abstract}
Um sistema de ensino regido pelos princípios de eficiência, competitividade e flexibilidade, em um processo taylorista de formação acelerada de operadores multifuncionais, disciplinados, estandardizados e facilmente recicláveis, isto é, disponíveis para serem utilizados de forma fluida, conforme a demanda variável (em tempo e lugar) do empregador (CASTRO, 2004, p. 80-81).
\end{abstract}

Castro critica algumas concepções de formação aligeirada, como se estivéssemos desenvolvendo uma produção taylorista, uma fabricação de trabalhadores, industrialização de sujeitos, em linha de montagem. O mesmo questiona, se o mercado de trabalho tem necessidade de recursos humanos qualificados ou de operadores 
descartáveis? O autor também tensiona a justificativa difundida, limitada, por sinal, de que muitas vezes a razão do desemprego está na falta de qualificação. Torna-se prudente lembrar que a racionalidade do sistema capitalista pressupõe um exército de reserva, como ameaça constante para o trabalhador empregado, precarizando, fragilizando as condições do trabalhador, como estratégia competitiva, onde os mais produtivos permanecem. Assim, mesmo que os índices de escolaridade sejam elevados, ainda haverá taxas de desemprego. Nesse sentido, justifica-se ainda a formação plural e crítica destes docentes frente a necessidade de disponibilizar uma consistente formação geral para que o trabalhador não seja facilmente substituído.

Seguindo este viés, Arroyo (2010) expõe:

A crise dessa mediação trabalho-educação é um dos elementos que tocam de maneira mais radical na crise da relação entre políticas educacionais e desigualdades. O trabalho, prometido como mediador da correção das desigualdades, torna-se uma das fronteiras mais cruéis de aumento e aprofundamento das desigualdades. O Estado-solução, corretor das desigualdades, passa a cumprir o papel da regulação da crise estrutural do trabalho, seja pela flexibilização dos direitos do trabalho, da estabilidade dos salários, seja deixando as relações de trabalho à mercê do mercado, de sua segmentação ou da polarização entre trabalhos, qualificação, salários (ARROYO, 2010, p. 1399).

De acordo com isso, inferimos que o modo de produção capitalista aumenta e aprofunda as desigualdades, em virtude da crueldade existente, da supervalorização das perspectivas lucrativas, fragmentando os direitos dos trabalhadores e debilitando as condições de trabalho.

Nesta parte do artigo, analisamos as diversas influências que o educador da educação profissional precisa considerar para o exercício de sua atuação. Resgatamos os pressupostos da formação inicial e continuada, como também esclarecemos as concepções de trabalho e pesquisa como princípios educativos, cultura, ciência e tecnologia.

\section{A ARTICULAÇÃo ENTRE O ENSINO, A PESQUISA E A EXTENSÃO}

O primeiro ponto que enfatizamos é que o exercício docente não pode desvincular sua formação da atuação e da realidade social e histórica. Partindo desse pressuposto, avançamos defendendo sua contribuição na necessária articulação entre o ensino, a pesquisa e a extensão e seu caráter indissociável, indissolúvel. Ao adotarmos uma postura de abertura, apoiada nesse tripé estaremos qualificando o processo educacional, permitindo a aprendizagem contextualizada e significativa, vinculada ao meio social, compromisso da educação.

A educação profissional não possui uma expertise em relação à articulação entre o ensino, a pesquisa e a extensão, e como tudo que é novo, está posto como algo desafiador. Essa característica inovadora vem sendo estimulada após a 
institucionalização dos Institutos Federais, no findar do ano de 2008. Em decorrência dessa falta de experiência é importante conhecer os elos estabelecidos pelas universidades, como instituições com tradição consolidada na indissociabilidade entre ensino, pesquisa e extensão.

Para Libâneo (1994), o ensino constitui-se o principal meio e fator da educação, mesmo que não seja o único e, por isso, destaca-se como campo principal da instrução e da educação. $O$ ensino corresponde às ações, aos meios e às condições para a realização da aprendizagem. Em relação à educação profissional, a instrução de técnicas e procedimentos práticos é necessária, mas, além desta face, há a educação com seu conceito mais amplo e multidimensional, em uma abertura para o diálogo interdisciplinar e a construção dos saberes.

Ademais, o ensino precisa problematizar as circunstâncias, muitas vezes dadas como naturais. $O$ ensino deve aguçar o espírito crítico e tornar o estudante um cidadão, apto a reivindicar melhores condições de trabalho e respeito para com sua vida, a natureza e a própria sociedade. Também, precisa agir em prol de seus direitos e 0 cumprimento de seus deveres com responsabilidade social. Frigotto pontua:

O que dizer aos trabalhadores? Reforçar, pura e simplesmente, a tese oficial de
que a escolarização complementada por alguma formação profissional confere
"empregabilidade" é, no mínimo, má fé. Por outro lado, afirmar que não adianta
lutar por mais e melhor educação, é, mais do que matar a esperança, eliminar
um espaço importante para a construção de um outro projeto, contra-
hegemônico. (FRIGOTTO, 1998, p. 69).

Com base nesta concepção, em um país permeado por contradições é primordial lutar por educação, pela democratização do conhecimento, pela ampliação da consciência, perseguindo o crescimento cultural e até buscando um patamar mais elevado de humanidade.

De modo mais diversificado temos o conceito de pesquisa. No entendimento de Demo (2005), a pesquisa deve ser vista como um processo social que perpassa toda a vida do professor e do aluno, assim a mesma pode ser compreendida como descoberta e criação. Pesquisar envolve a construção, produção e o resgate do conhecimento. Pesquisar coincide com a vontade de viver, de mudar, de transformar, de recomeçar. Demo sugere que dialogar com a realidade talvez seja a definição mais adequada de pesquisa, porque a compreende como princípio científico e educativo, que realiza a mediação no processo de ensino-aprendizagem. Em outra obra, este autor assim confirma: "Em primeiro lugar, pesquisa significa diálogo crítico e criativo com a realidade, culminando na elaboração própria e na capacidade de intervenção. Em tese, pesquisa é a atitude do aprender a aprender, e, como tal, faz parte de todo processo educativo emancipatório" (DEMO, 1998, p.128). Dando sequência, o autor revela que quem pesquisa tem o que ensinar, quem não pesquisa só ensina o que copia.

Frente à importância da pesquisa, Nosella (2005, p.235) enfatiza: "a competência profissional, quando resultado de pesquisa sem preconceitos, profunda, socialmente benéfica, historicamente avançada, efetua uma forma de compromisso político". Ou seja, 
no processo de pesquisa, de investigação podemos priorizar a ciência comprometida, colaborativa que beneficie a sociedade como um todo.

No que diz respeito à extensão, os programas de extensão oportunizam aos estudantes vivenciar o pertencimento, o planejamento, o criar, o construir, a aplicação e o retorno. E esta vivência é concretizada com a participação dos discentes em projetos oferecidos ou criados em conjunto com o grupo do curso de formação em um processo de integração daquilo que ocorre no processo de formação profissional, dentro da sala de aula e que possibilita o enriquecimento por meio da aplicabilidade fora da sala de aula (na territorialidade), muitas vezes respondendo à problemas sociais. Freire, o mais reconhecido internacionalmente educador brasileiro, ressalta:

\begin{abstract}
A captação e a compreensão da realidade se refazem, ganhando um nível que até então não tinham. Os homens tendem a perceber que sua compreensão e que a 'razão' da realidade não estão fora dela, como, por sua vez, ela não se encontra deles dicotomizada, como se fosse um mundo à parte, misterioso e estranho, que os esmagasse. (FREIRE, 1987, p. 96).
\end{abstract}

Por meio de projetos de extensão é realizado o contato direto com o meio no qual estamos inseridos e, assim, é aguçada a compreensão da realidade, reconhecidas as possibilidades e os desafios. E ainda, podemos realizar a verificação da validade do conhecimento, dos saberes e experiências nesse contexto, com a difusão do que está aprendendo. Outra possibilidade é aguçar a curiosidade levantando dúvidas para produzir novos conhecimentos que venham a facilitar, melhorar a vida da comunidade. Nesse formato, a extensão pode ser analisada como uma forma de dar um retorno social, uma contribuição da educação para a sociedade, ou ainda, ao conhecer a realidade, perceber fatores que necessitam de dedicação e novas pesquisas para sua melhoria.

Saviani (1986) considera que a extensão é a articulação entre as instituições educativas e a sociedade. É a maneira de socializar, difundir os conhecimentos como força viva capaz de elevar o nível geral e cultural da sociedade. Assim, a extensão, estende os saberes de modo assistencial, na tentativa de expandir, ofertar para a comunidade seus conhecimentos. A extensão faz com que haja consciência sobre 0 vínculo e o comprometimento em melhorar as condições da sociedade como um todo, e não apenas dos sujeitos envolvidos na aprendizagem.

De modo bem sucinto, podemos conceber o ensino, como uma prática de construção do conhecimento, por meio de metodologias que façam com que o educando alcance um estágio cognitivo superior. Em relação à pesquisa, podemos concebê-la como um processo reflexivo de investigação de conhecimentos já elaborados ou ainda a produção de conhecimentos novos. Da mesma maneira, a extensão é concebida como a disseminação, o compartilhamento, a disponibilização dos conhecimentos a serviço da comunidade, num contexto mais prático e dinâmico. Ao seguir estas pistas concluímos que estas três perspectivas estão em contínua interlocução, uma vez que, ao pesquisar, alimento o ensino e a extensão; ao ensinar, posso estimular a pesquisa e a extensão; e ao praticar a extensão posso instrumentalizar a pertinência do ensino e a relevância e o direcionamento da pesquisa. Ou seja, estas três vertentes vêm para qualificar a tarefa 
educativa como uma possibilidade de exercer a responsabilidade social de forma técnica e política sobre o exercício docente.

Ao assumirmos a articulação do ensino, pesquisa e extensão como premissas da educação profissional, científica e tecnológica estaremos indo na contramão do percurso de perpetuação das desigualdades sociais, em virtude de que este conjunto permite a conscientização e o diálogo entre o conhecimento e a cultura produzidos e as necessidades do meio social.

Frente ao exposto, compreendemos que, ao nos apoiarmos nos pilares do ensino, pesquisa e extensão, podemos transitar da educação para a sociedade, dialogando sobre suas problemáticas, conscientizando, principalmente, para a situação desafiadora da desigualdade socioeconômica e pensando em como podemos contribuir para que a educação profissional seja um dos caminhos que corroborem para a justiça social.

\section{TECENDO ALGUMAS CONSIDERAÇÕES FINAIS}

"O educador de hoje, concretamente,
como poderá exercer seu
engajamento político e
sua competência técnica?"

(Paolo Nosella)

Nesse artigo, desenvolvemos uma reflexão acerca da formação de educadores para a educação profissional tratando de aspectos centrais. Salientamos, que as notas e concepções expostas tem um caráter inacabado, podendo ser questionadas e reformuladas. Adotamos uma postura provocativa e levantamos várias indagações, a fim de propiciar a reflexão e quem sabe um debate a partir das mesmas.

O principal argumento tecido é de que a formação docente para a educação profissional precisa estar sustentada em dois campos de conhecimento: os saberes técnico-científicos e os saberes pedagógicos-educacionais e permear tais qualificações em um comprometimento político, afirmado com a classe trabalhadora com a finalidade maior da transformação social. Não basta dominar o conteúdo da matriz técnica e não entender de procedimentos didáticos, de metodologia e de como aprendemos. Como também, o educador desta área, além de uma consistente formação específica, precisa compreender as diversas variáveis do mundo do trabalho e nutrir saberes da formação geral. Nesse cenário, alertamos para que este profissional exerça sua atuação em perspectivas mais profundas, não apenas preparando um trabalhador adaptável, flexível, facilmente descartável, segundo as (de)formações do mercado. Em relação à formação do educador, também pontuamos que a mesma necessita de políticas perenes e articuladas desde seu caráter inicial, e ainda precisa ser continuada, permanente, constante, pois tem característica de (in)conclusão, em virtude que a educação é um processo dinâmico inserido socialmente e deve acompanhar as mudanças e inovações sociais. 
Nesta perspectiva, também abordamos alguns pilares da educação profissional: trabalho e pesquisa como princípios educativos, cultura, ciência e tecnologia. Tais pilares devem estar em integração, com vistas para uma formação integral, como sujeito, cidadão-trabalhador. Nesta direção, Gracindo e Monlevade contribuem, destacando que as instituições educativas têm uma missão política, pedagógica e econômica substantiva:

\begin{abstract}
Muitas pessoas acham que a educação serve para preparar mão de obra para o mercado. Já outras, acham que a educação e a escola têm como objetivo garantir a reprodução do conhecimento acumulado para as gerações futuras. Existem ainda aqueles que compreendem que a escola deve se preocupar com a formação do cidadão. As primeiras privilegiam o mundo do trabalho e, dessa forma, veem na escola a função econômica como a mais importante. O segundo grupo valoriza mais a função técnica da escola, com a transmissão do conhecimento. O terceiro grupo focaliza a função política da escola como preponderante, dando destaque aos valores, posturas e ações a serem construídos no ambiente escolar. Vale ressaltar que parece haver um pouco de verdade em cada uma dessas manifestações. Percebemos que é importante formar pessoas para ingressarem no mercado de trabalho, que é importante proporcionar a construção de conhecimento e que também é importante garantir que a escola seja um espaço onde o estudante se torne um cidadão, sujeito de sua própria história. Podemos, então, concluir que a escola tem uma tripla função: política, pedagógica e econômica (GRACINDO, MONLEVADE, 2013, p. 26-27).
\end{abstract}

Com esta concepção, é demonstrado como é importante formar pessoas para o mundo do trabalho, com qualificada formação geral e à luz de princípios de cidadania. Desse modo, os educadores e educadoras da educação profissional também necessitam contribuir com essa tripla função: política, pedagógica e econômica.

Por fim, nesse artigo articulamos a proposta de formação dos educadores da educação profissional com o tripé: ensino, pesquisa e extensão. Frente ao exposto, educar e ensinar pressupõem a pesquisa e a disseminação do conhecimento. Já a extensão demonstra a preocupação, o vínculo e o compromisso com a comunidade por meio de retorno social, propiciando o entrelaçamento da teoria com a prática.

Por meio desse texto, também refletimos sobre o trabalho a fim de que o educador da educação profissional, com sólida formação crítica, geral e com fundamentação técnica, torne-se uma referência como intelectual, mediador e problematizador para que o educando consiga se inserir nesse meio com compromisso técnico e princípios de cidadania. Ser trabalhador na educação é vivenciar as vicissitudes do mundo do trabalho, refletir cientificamente os processos e relações sociais e também semear esperanças, disseminar o espírito de solidariedade, de cooperação, na luta por condições mais justas.

\title{
REFERÊNCIAS
}

ARAUJO, R. M. de L. Formação de Docentes para a Educação Profissional e Tecnológica: por uma pedagogia integradora da educação profissional. Trabalho \& 
Educação. Belo Horizonte, vol. 17, n.2. mai.-ago. 2008. Disponível em:

http://www.ufpa.br/ce/gepte/imagens/artigos/formacao\%20de\%20professores\%20e\%20di datica\%20de\%20ep\%20cap..pdf. Acesso em: 04 jun. 2015.

ARROYO, M. Politicas Educacionais e Desigualdades: à procura de novos significados. Educação e Sociedade. Campinas, v.31, n.113, p.1381-1416, out.-dez. 2010.

Disponível em: http://www.scielo.br/pdf/es/v31n113/17.pdf. Acesso em: 23 jun. 2015.

ARRUDA, M. A articulação trabalho-educação visando uma democracia integral. In: GOMEZ, Carlos Minayo. [et. al.] Trabalho e Conhecimento: dilemas na educação do trabalhador. 6.ed. São Paulo: Cortez, 2012, p. 83-101.

BRASIL, Ministério da Educação. Diretrizes Curriculares Nacionais Gerais da Educação Básica. Brasília: MEC, 2013. Disponível em:

file:///C:/Users/aluno/Downloads/diretrizes curiculares nacionais 2013\%20(3).pdf.

Acesso em: 22 jun. 2015.

BRASIL. Planalto. Constituição da República Federativa do Brasil (1988). Brasília.

Disponível em: http://www.planalto.gov.br/ccivil 03/constituicao/constituicao.htm. Acesso em: 05 jun. 2015.

CASTRO, R. P. Escola e Mercado: a escola face à institucionalização do desemprego e da precariedade na sociedade colocada ao serviço da economia. Perspectiva.

Florianópolis, v. 22, n.01, p.79-92, jan./jun. 2004. Disponível em:

https://periodicos.ufsc.br/index.php/perspectiva/article/view/10084. Acesso em: 23 jun. 2015.

CIAVATTA, M. Os estudos comparados em formação profissional. Niterói: UFF, 2004.

DAMASCENA, E. A.; NASCIMENTO, A. C. V.; MOURA, D. H. Formação de

professores para a educação profissional: o que apontam os dispositivos legais mais recentes (2015-2017). Disponível em:

https://edisciplinas.usp.br/pluginfile.php/4684892/mod resource/content/2/TEXTO\%20DA NTE\%201.pdf. Acesso em: 12 nov. 2019.

DEMO, P. Desafios Modernos da Educação. 7. ed. Petrópolis, RJ: Editora Vozes, 1998.

DEMO. Educar pela pesquisa. Campinas: Autores Associados, 2003.

DEMO. Pesquisa: princípio científico e educativo. São Paulo: Cortez, 2005.

FREIRE, P. Pedagogia do Oprimido. 17. Ed. Rio de Janeiro: Paz e Terra, 1987.

GOMEZ, C. M. et. al. Trabalho e Conhecimento: dilemas na educação do trabalhador. 6.ed. São Paulo: Cortez, 2012.

GRACINDO, R. V.; MONLEVADE, J. A. C. de. Gestão democrática nos sistemas e na escola. 4.ed. Cuiabá: Universidade Federal de Mato Grosso/Rede E-Tec Brasil, 2013. 
KUENZER, A. Ensino de Segundo Grau: o trabalho como princípio educativo. São Paulo: Cortez, 1988.

LIBÂNEO, J. C. Didática. São Paulo: Cortez, 1994.

MACHADO, L. R. S. Formação de professores para a educação profissional e tecnológica: perspectivas históricas e desafios contemporâneos. In: INEP. Formação de professores para educação profissional e tecnológica. Brasília: INEP, 2008.

MOURA, D. H. Trabalho e formação docente na educação profissional. Dados eletrônicos. Curitiba: Instituto Federal do Paraná, 2014. (Coleção formação pedagógica; v. 3).

NOSELLA, P. Compromisso Político e Competência Técnica: vinte anos depois. Educação e Sociedade. Campinas, vol.26, n. 90, jan.-abr. 2005. Disponível em: http://www.scielo.br/pdf/es/v26n90/a10v2690.pdf. Acesso em: 16 mar. 2016.

SAVIANI, D. Ensino público e algumas falas sobre universidade. São Paulo: Cortez/Autores Associados, 1986. 